\title{
Brown adipose tissue activity after a high-calorie meal in humans.
}

Citation for published version (APA):

Vosselman, M. J., Brans, B., van der Lans, A. A., Wierts, R., van Baak, M. A., Mottaghy, F. M.,

Schrauwen, P., \& van Marken Lichtenbelt, W. D. (2013). Brown adipose tissue activity after a high-calorie meal in humans. American Journal of Clinical Nutrition, 98(1), 57-64.

https://doi.org/10.3945/ajcn.113.059022

Document status and date:

Published: 01/01/2013

DOI:

10.3945/ajcn.113.059022

Document Version:

Publisher's PDF, also known as Version of record

Document license:

Taverne

Please check the document version of this publication:

- A submitted manuscript is the version of the article upon submission and before peer-review. There can be important differences between the submitted version and the official published version of record.

People interested in the research are advised to contact the author for the final version of the publication, or visit the DOI to the publisher's website.

- The final author version and the galley proof are versions of the publication after peer review.

- The final published version features the final layout of the paper including the volume, issue and page numbers.

Link to publication

\footnotetext{
General rights rights.

- You may freely distribute the URL identifying the publication in the public portal. please follow below link for the End User Agreement:

www.umlib.nl/taverne-license

Take down policy

If you believe that this document breaches copyright please contact us at:

repository@maastrichtuniversity.nl

providing details and we will investigate your claim.
}

Copyright and moral rights for the publications made accessible in the public portal are retained by the authors and/or other copyright owners and it is a condition of accessing publications that users recognise and abide by the legal requirements associated with these

- Users may download and print one copy of any publication from the public portal for the purpose of private study or research.

- You may not further distribute the material or use it for any profit-making activity or commercial gain

If the publication is distributed under the terms of Article $25 \mathrm{fa}$ of the Dutch Copyright Act, indicated by the "Taverne" license above, 


\title{
Brown adipose tissue activity after a high-calorie meal in humans ${ }^{1-3}$
}

\author{
Maarten J Vosselman, Boudewijn Brans, Anouk AJJ van der Lans, Roel Wierts, Marleen A van Baak, Felix M Mottaghy, \\ Patrick Schrauwen, and Wouter D van Marken Lichtenbelt
}

\begin{abstract}
Background: Studies in rodents have shown that brown adipose tissue (BAT) is activated on food intake, thereby reducing metabolic efficiency.

Objective: The current study investigated whether a single highcalorie, carbohydrate-rich meal activates BAT in lean human adults. Design: BAT activity was studied in 11 lean adult men [age: $23.6 \pm$ $2.1 \mathrm{y}$; body mass index (BMI; in $\mathrm{kg} / \mathrm{m}^{2}$ ): $22.4 \pm 2.1$ ] after consumption of a high-calorie, carbohydrate-rich meal (1622 $\pm 222 \mathrm{kcal} ; 78 \%$ carbohydrate, $12 \%$ protein, $10 \%$ fat). BAT activity during $2 \mathrm{~h}$ of mild cold exposure served as a positive control experiment. BAT activity was assessed by $\left[{ }^{18} \mathrm{~F}\right]$ fluorodeoxyglucose (FDG)-positron emission tomography-computed tomography. Energy expenditure was measured by indirect calorimetry.

Results: Postprandial $\left[{ }^{18} \mathrm{~F}\right] \mathrm{FDG}$ uptake was significantly higher in BAT [1.65 \pm 0.99 mean standard uptake value $\left.\left(\mathrm{SUV}_{\text {mean }}\right)\right]$ than in subcutaneous $\left(0.35 \pm 0.15 \mathrm{SUV}_{\text {mean }} ; P<0.05\right)$ and visceral $\left(0.49 \pm 0.24 \mathrm{SUV}_{\text {mean }} ; P<0.05\right)$ white adipose tissue and liver $\left(0.95 \pm 0.28 \mathrm{SUV}_{\text {mean }} ; P<0.05\right)$. Postprandial BAT activity was lower than cold-induced BAT activity $\left(7.19 \pm 2.09 \mathrm{SUV}_{\text {mean }}\right)$. However, postprandial BAT activity may have been underestimated because of high postprandial $\left[{ }^{18} \mathrm{~F}\right] \mathrm{FDG}$ uptake in skeletal muscle compared with cold $(1.36 \pm 0.31$ compared with $0.59 \pm 0.07$ SUV $_{\text {mean }}, P<0.05$ ), which reduces $\left[{ }^{18} \mathrm{~F}\right] \mathrm{FDG}$ bioavailability for BAT and other tissues. No direct relation was found between BAT and diet-induced thermogenesis (DIT).

Conclusions: Glucose uptake in BAT increases after a meal in humans, which indicates a role for BAT in reducing metabolic efficiency. However, the quantitative contribution of BAT to DIT relative to other tissues, such as skeletal muscle, remains to be investigated. This trial was registered at www.controlled-trials.com as ISRCTN21413505. Am J Clin Nutr 2013;98:57-64.
\end{abstract}

\section{INTRODUCTION}

Brown adipose tissue (BAT) ${ }^{4}$ is currently considered as a potential preventive and therapeutic target for the combat against obesity and its related metabolic diseases because of its high metabolic capacity. It is now well established that BAT is functional in human adults $(1,2)$ and that it could contribute to coldinduced thermogenesis (CIT) (3-6). Indeed, BAT is well known for its role in maintaining thermal homeostasis in small rodents and infants during cold challenges (7). However, in addition to its thermoregulatory function, BAT may also be involved in maintaining energy balance. Interestingly, it has been shown that coldinduced BAT activity is lower in obese people $(1,6,8)$.
It was originally believed that deletion of uncoupling protein1 , which is crucial for heat production, did not induce obesity in mice spontaneously. However, a recent study showed that these mice do develop obesity during thermoneutral conditions (9). Uncoupling protein-1-ablated mice are more susceptible to obesity during overfeeding because of a high metabolic efficiency, which indicates that a greater fraction of the ingested energy is saved in body energy stores (9). In contrast, wild-type rodents have a lower metabolic efficiency because BAT wastes excessive caloric intake, as shown by increased BAT recruitment and enhanced norepinephrine-induced thermogenesis during high-fat feeding and voluntary overeating $(9,10)$. It was believed that this decrease in metabolic efficiency during overfeeding was a result of nutrient-deficient or unbalanced diets. In 1999, Stock explored this theory in humans, and in his reanalysis of 12 overfeeding studies he showed that overfeeding lowprotein diets resulted in a lower weight gain than expected based on caloric intake and hypothesized that this was because of increased thermogenesis and thus possibly via BAT activation (11). The role of BAT in maintaining energy balance is, however, not generally supported (12).

In addition to this adaptive response of BAT on long-term overfeeding nutrient-deficient diets, single meals are also known to induce an increase in thermogenesis, known as diet-induced thermogenesis (DIT), and comprises an obligatory and a facultative part (13). The obligatory component of DIT includes the required energy needed for digestion, absorption, distribution, and storage of the nutrients, whereas the facultative part wastes

\footnotetext{
${ }^{1}$ From the Department of Human Biology, NUTRIM School for Nutrition, Toxicology and Metabolism, Maastricht University Medical Center+ Maastricht, Netherlands (MJV, AAJJvdL, MAvB, PS, and WDvML), and the Department of Nuclear Medicine, Maastricht University Medical Center+ Maastricht, Netherlands (BB, RW, and FMM).

${ }^{2}$ Supported by the Netherlands Organization for Scientific Research (TOP 91209037 to WDvML) and the EU FP7 project DIABAT (HEALTH-F22011-278373).

${ }^{3}$ Address correspondence to WD van Marken Lichtenbelt, NUTRIM, School for Nutrition, Toxicology and Metabolism, Department of Human Biology, Maastricht University, PO Box 616, 6200 MD Maastricht, Netherlands. E-mail: markenlichtenbelt@maastrichtuniversity.nl.

${ }^{4}$ Abbreviations used: BAT, brown adipose tissue; CIT, cold-induced thermogenesis; CT, computed tomography; DIT, diet-induced thermogenesis; FDG, fluorodeoxyglucose; FTN, fasted thermoneutral; PET, positron emission tomography; SNS, sympathetic nervous system; $\mathrm{SUV}_{\text {mean }}$, average standard uptake value; WAT, white adipose tissue.

Received January 19, 2013. Accepted for publication April 24, 2013.

First published online May 29, 2013; doi: 10.3945/ajcn.113.059022.
} 
a fraction of the ingested energy as heat (14). Several rodent studies have demonstrated that a single meal leads to BAT activation (15-20), and moreover that cold-acclimated animals have increased DIT (21). Therefore, these rodent data suggest that even after a single meal, BAT can be activated to waste a part of the energy intake as heat. Again, such evidence is lacking in humans. Here we set out to investigate whether a single meal is able to activate BAT in humans. Because it is thought that the sympathetic nervous system (SNS) plays an important role in facultative DIT, and because it is known from human studies that of all macronutrients carbohydrates are the most potent SNS stimulators (14), we tested the effects of a high-calorie, high-carbohydrate meal on BAT activity in humans and compared this with cold-activated BAT activity as a positive control.

\section{SUBJECTS AND METHODS}

\section{Subjects}

Eleven healthy lean men [age: $23.6 \pm 2.1 \mathrm{y}$; BMI (in $\mathrm{kg} / \mathrm{m}^{2}$ ): $22.4 \pm 2.1]$ were recruited by advertising in the Maastricht University Medical Centre+. All subjects provided written informed consent and underwent a standard medical examination. The local medical ethical committee approved the study protocol, and all subjects were treated according to the Declaration of Helsinki of 1975, as revised in 1983.

\section{Study design and measurements}

BAT activity was determined during 2 experimental conditions, after the intake of a high-calorie meal and during mild cold exposure. The mild cold experiment was conducted in 6 of 11 subjects and served as a positive control. The experiments were conducted in Maastricht (Netherlands) from September through December, with outside temperatures varying between 0 and $20^{\circ} \mathrm{C}$. Subjects arrived in the morning after an overnight fast and were asked to refrain from heavy exercise on the previous day. After their arrival, the subjects ingested a telemetric pill (HT150002; CoreTemp) for core temperature measurement, and a cannula was inserted in the antecubital vein for blood sampling. Subsequently, the subjects were equipped with wireless temperature sensors (iButtons, Maxim integrated) at the 14 sites prescribed by International Standards Organization standard 9886:2004 (Ergonomics-Evaluation of thermal strain by physiologic measurements, Geneva, Switzerland), a heart rate monitor across the chest (Polar T31), and a blood pressure cuff on the left upper arm (Cresta) to measure skin temperatures, heart rate, and blood pressure, respectively. Laser Doppler probes were attached for skin perfusion measurements at the ventral side of the hand at the base of the thumb, at the ventral side of the hallux (Perimed PF4000), at the ventral side of the forearm halfway between the elbow and the wrist, and at the abdomen halfway between the umbilicus and the left lateral side of the body (Perimed PF5000). Subjects were measured in a specially equipped air-permeable tent (Colorado altitude training), in which ambient temperature could be tightly controlled. During the measurements, subjects wore standardized clothing (0.49 clo).

The meal intake experiment started with a baseline measurement of $45 \mathrm{~min}$ (Figure 1), after which each subject ingested a high-calorie (average: $1622 \pm 222 \mathrm{kcal}$ ), carbohydrate-rich (78\% carbohydrate, $10 \%$ fat, and $12 \%$ protein) meal consisting of $50 \%$ of their daily required energy intake. The subject's total daily required energy intake was based on the basal metabolic rate determined by the Harris and Benedict formula (22) multiplied by the physical activity level, which was based on the Baecke Questionnaire (23). The meal was served by the researcher in a liquid form (Nutriprotein and Nutrical; Nutricia) to obtain maximal uptake rate in the gastrointestinal tract. After the subjects finished the meal (within $15 \mathrm{~min}$ ), energy expenditure was measured for $2 \mathrm{~h}$. The $\left[{ }^{18} \mathrm{~F}\right]$ fluorodeoxyglucose (FDG) tracer $(50 \mathrm{MBq}, 1.35 \mathrm{mCi})$ was injected 75 min after the completion of the meal, because pilot studies $(n=6)$ in our laboratory showed the highest peak in postprandial energy expenditure at this time point, assuming maximal BAT activity. For the analysis of postprandial energy expenditure, a stable period of $20 \mathrm{~min}$ after the tracer injection was averaged. DIT was measured as the increase (in percentage) in energy expenditure during these 20 min compared with baseline. This period was chosen to relate DIT to BAT activity, because the latter is determined in the posttracer period as well. Blood samples were

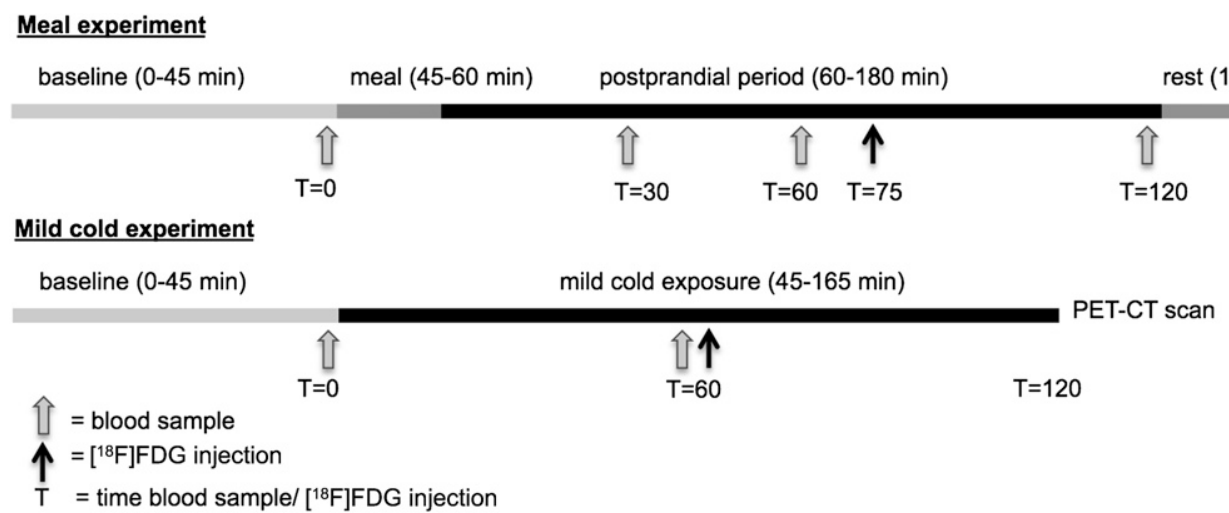

FIGURE 1. Study protocol. Both experiments started with a baseline period of $45 \mathrm{~min}$ at $25^{\circ} \mathrm{C}$. A blood sample was collected at the end of this period. In the meal experiment, subjects were asked to ingest the meal within $15 \mathrm{~min}$. The postprandial period lasted for 120 min. One hour and 15 min after the meal, the $\left[{ }^{18} \mathrm{~F}\right]$ FDG tracer $(75 \mathrm{~min})$ was injected followed by the PET-CT scan $1 \mathrm{~h}$ later. A rest period of 15 min was held to standardize the time between injection and PET-CT scan (1 h). Blood samples were collecetd 30, 60, and $120 \mathrm{~min}$ after the meal. The mild cold exposure lasted for 120 min, and $1 \mathrm{~h}$ after the onset of the cold exposure, a blood sample was collected and the $\left[{ }^{18} \mathrm{~F}\right]$ FDG tracer was injected. The PET-CT scan was conducted $1 \mathrm{~h}$ after the $\left[{ }^{18} \mathrm{~F}\right] \mathrm{FDG}$ injection $(120$ min). CT, computed tomography; FDG, fluorodeoxyglucose; PET, positron emission tomography; T, time. 
drawn during baseline and 30, 60, and 120 min after the meal. The subjects were transferred to the positron emission tomography (PET) computed tomography (CT) scanner (Gemini TF PET-CT; Philips) $1 \mathrm{~h}$ after the tracer injection in both experiments to measure BAT activity. Although we are aware that $\left[{ }^{18}\right.$ F]FDG uptake measures glucose uptake, and not BAT oxidative metabolism and thermogenesis directly, we used BAT activity and $\left[{ }^{18} \mathrm{~F}\right] \mathrm{FDG}$ uptake as reciprocal terms.

The mild cold experiment consisted of a baseline measurement of $45 \mathrm{~min}$, followed by $2 \mathrm{~h}$ of mild cold exposure in which we used a personalized cooling protocol (24) to obtain maximal nonshivering thermogenesis. We used the same posttracer period as in the meal experiment for cold-induced energy expenditure analysis. CIT was defined as the percentage increase in energy expenditure during this period compared with baseline. The $\left[{ }^{18} \mathrm{~F}\right] \mathrm{FDG}$ tracer was injected $1 \mathrm{~h}$ after the onset of cold exposure. Blood samples were drawn during baseline and after $1 \mathrm{~h}$ of cold exposure.

\section{PET protocol and analysis}

The PET-CT scanning protocol and analysis were similar to those in our previous studies using static imaging (24), in which a low-dose CT scan $(120 \mathrm{kV}, 30 \mathrm{mAs})$ preceded the PET scan. The PET scan was used to determine FDG uptake, and the CT image was used for attenuation and scatter correction of the PET scan. We used PMOD software (version 3.0; PMOD Technologies) for the analysis of BAT activity. The PET images were checked for remaining radioactivity at the injection site, and these concentrations were all $<1 \%$ of the total activity of $\left[{ }^{18} \mathrm{~F}\right] \mathrm{FDG}$ present in the body at the time of scanning.

Together, the researcher and a nuclear-medicine physician (BB) analyzed the PET-CT images. We analyzed the average standard uptake value $\left(\mathrm{SUV}_{\text {mean }}\right)$ in the cold and meal experiment in supraclavicular BAT, subcutaneous and visceral white adipose tissue (WAT), skeletal muscle, liver, and brain. The $\mathrm{SUV}_{\text {mean }}$ of each tissue was calculated by selecting cubes as volume of interests on the relevant tissues. The same anatomic locations were used in the analysis of both experiments. The $\mathrm{SUV}_{\text {mean }}$ of BAT was measured in the supraclavicular fat area (total volume: $2.67 \mathrm{~cm}^{3}$ ). To determine the average $\left[{ }^{18} \mathrm{~F}\right] \mathrm{FDG}$ uptake in the deltoid muscle and the triceps and biceps brachii muscle, we analyzed the middle (thickest) part of these muscles in both arms. The uptake in the erector spinae muscle was measured in the cervical (C-7), thoracic (T-8), and lumbar (L-3) part of the muscle (total volume in muscle: $32 \mathrm{~cm}^{3}$ ). The subcutaneous WAT was measured in the dorsolumbar region near vertebrae L-3 and L-4 $\left(8 \mathrm{~cm}^{3}\right)$, whereas the visceral WAT was measured behind the xiphoid $\left(0.14 \mathrm{~cm}^{3}\right)$. The middle part of the liver was chosen for analysis, and we avoided uptake in large blood vessels by carefully distinguishing between the liver segments $\left(4 \mathrm{~cm}^{3}\right)$. Brain activity was measured in the right and left cerebellum $\left(8 \mathrm{~cm}^{3}\right)$. Adipose tissue was distinguished from muscle tissue by means of Hounsfield units (CT scan), in which adipose tissue was considered to lie within -10 to -180 Hounsfield units and skeletal muscle between 15 and 100 Hounsfield units.

\section{Blood analysis}

Blood was collected from the antecubital vein to measure several blood variables. Plasma concentrations of free fatty acids
(NEFA-HR set; Wako Chemicals), free glycerol (Glycerol kit; R-Biopharm), total glycerol (ABX Triglyceriden CP; Radiometer), and glucose (ABX Glucose HK CP; Radiometer) were measured on a COBAS FARA centrifugal spectrophotometer (Roche Diagnostica). Plasma triglyceride concentrations were calculated by subtracting free glycerol from the total glycerol concentrations, and serum insulin was analyzed on a Gamma Counter (2470 Automatic Gamma Counter Wizard ${ }^{2}$ Wallac; PerkinElmer) with a Human Insulin specific RIA kit (Millipore). Plasma norepinephrine and adrenaline were analyzed by using reagents from Recipe Chemicals and Instruments with HPLC through electrochemical detection.

\section{Statistical analysis}

Statistical analysis was performed with IBM SPSS Statistics18.0 for Macintosh. Reported data are expressed as means \pm SDs. The differences between baseline and cold exposure were compared with a Wilcoxon's test $(n=6)$. Paired-sample $t$ tests were used to compare the difference between baseline and dietary intake $(n=11)$. The $\mathrm{SUV}_{\text {mean }}$ values for the various tissues in the cold and meal experiment were compared with a Wilcoxon's test $(n=6)$. Blood variables within the meal experiment were analyzed by one-factor ANOVA with Bonferroni correction for post hoc analysis. Spearman rank correlation $(n=6)$ and Pearson correlation $(n=11)$ were performed to identify relations between variables. $P$ values $<0.05$ were considered statistically significant.

\section{RESULTS}

\section{Cold- and diet-induced thermogenesis}

Energy expenditure significantly increased in the postprandial phase compared with baseline $(P<0.001$; Figure 2A), with an average DIT of $19.9 \%$ (range: $6.9-31.3 \%$ ). During cold exposure, energy expenditure significantly increased from baseline as well $(P=0.028$; Figure $2 \mathrm{~A})$, with an average CIT of $13.1 \%$ (range: 7-17.1\%). No relation was found between CIT and DIT $(n=6)$. As expected, the respiratory quotient significantly increased after the meal $(P<0.001$; Figure $2 \mathrm{~B})$. Furthermore, carbohydrate oxidation increased after the meal $(P<0.001$; Figure 2C), whereas fat oxidation decreased $(P=0.027$; Figure $2 D)$. During cold exposure, there was a preference for the use of fat as a substrate as shown by the decrease in respiratory quotient $(P=0.041)$ and increase in fat oxidation $(P=0.028)$. The oxidation of carbohydrates decreased during cold exposure $(P=$ 0.046). The effects of both interventions on heart rate, blood pressure, and body temperatures are summarized in Table $\mathbf{1 .}$

\section{Glucose uptake in brown adipose tissue and additional tissues}

$\left[{ }^{18} \mathrm{~F}\right] \mathrm{FDG}$ uptake in the upper body is depicted in Figure 3, A and $\mathrm{B}$. Interestingly, average postprandial $\left[{ }^{18} \mathrm{~F}\right] \mathrm{FDG}$ uptake in BAT $\left(1.65 \pm 0.99 \mathrm{SUV}_{\text {mean }}\right)$ was markedly higher than that in subcutaneous $\left(0.35 \pm 0.15 \mathrm{SUV}_{\text {mean }} ; P<0.001\right)$ and visceral $\left(0.49 \pm 0.24 \mathrm{SUV}_{\text {mean }} ; P<0.001\right)$ WAT and in the liver $(0.95 \pm$ $0.28 \mathrm{SUV}_{\text {mean }} ; P=0.042$ ) (Figure $3 \mathrm{C}$ ). The average $\left[{ }^{18} \mathrm{~F}\right] \mathrm{FDG}$ uptake trended higher compared with skeletal muscle $(1.36 \pm$ $\left.0.31 \mathrm{SUV}_{\text {mean }}\right)$, although this difference was not statistically 

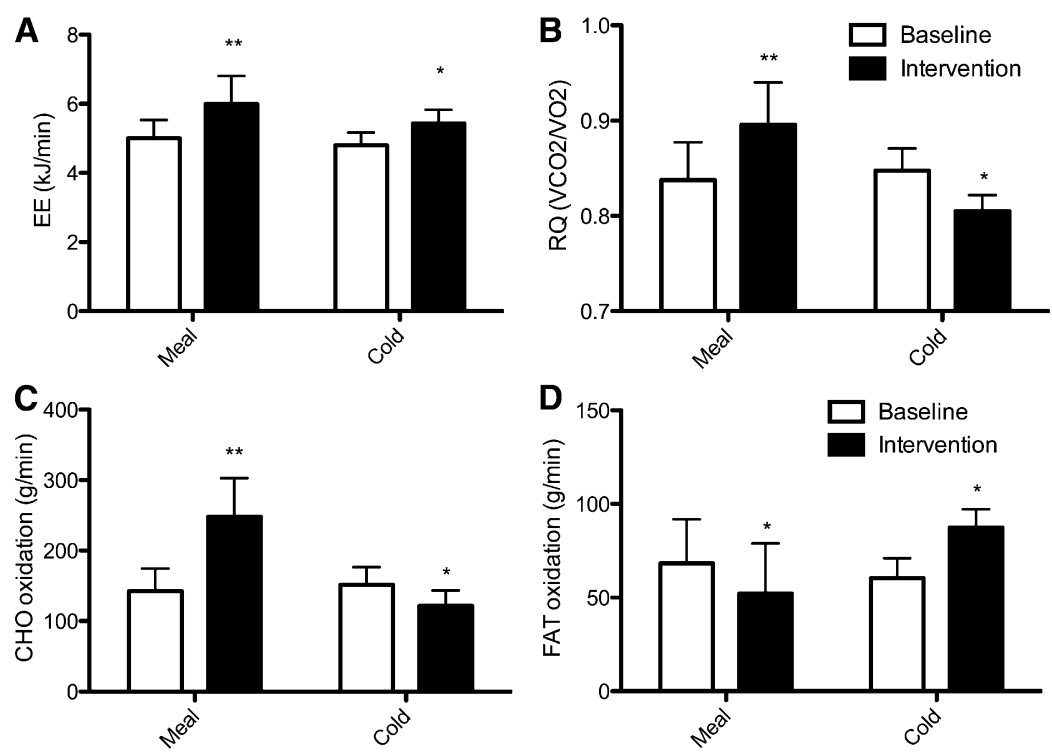

FIGURE 2. Mean ( \pm SD) energy expenditure (A), RQ (B), CHO oxidation (C), and fat oxidation (D) during baseline (white bars) and the intervention (black bars) in the postprandial state $(n=11)$ and during cold exposure $(n=6)$ measured during the posttracer period. Wilcoxon's signed-rank tests were used to measure the difference between both experiments. *Significantly different from baseline, $P<0.05$. **Significantly different from baseline, $P<0.001$. $\mathrm{CHO}$, carbohydrate; EE, energy expenditure; $\mathrm{RQ}$, respiratory quotient; $\mathrm{VO} 2$, oxygen consumption; $\mathrm{VCO}$, carbon dioxide consumption.

significant. The activity in BAT was comparable with that in the brain $\left(1.81 \pm 0.42 \mathrm{SUV}_{\text {mean }}\right.$; NS).

Cold exposure activated BAT, as shown by $\left[{ }^{18} \mathrm{~F}\right] \mathrm{FDG}$ uptake in the neck, supraclavicular, paraspinal, paraaortic, axillary, mediastinal, and perirenal regions in all subjects (Figure 3A, 3B). Also during cold exposure, $\left[{ }^{18} \mathrm{~F}\right] \mathrm{FDG}$ uptake was similar in BAT $\left(7.19 \pm 2.09 \mathrm{SUV}_{\text {mean }}\right)$ and brain $\left(7.19 \pm 0.74 \mathrm{SUV}_{\text {mean }}\right)$ (Figure 3D). Uptake of $\left[{ }^{18} \mathrm{~F}\right] \mathrm{FDG}$ in BAT was significantly higher than that in skeletal muscle $\left(0.59 \pm 0.07 \mathrm{SUV}_{\text {mean }} ; P=\right.$ $0.028)$, subcutaneous WAT $\left(0.18 \pm 0.05 \mathrm{SUV}_{\text {mean }} ; P=0.028\right)$, visceral WAT $\left(0.51 \pm 0.23 \mathrm{SUV}_{\text {mean }} ; P=0.028\right)$, and the liver $\left(1.83 \pm 0.28 \mathrm{SUV}_{\text {mean }} ; P=0.028\right)$.

Comparison of the meal with cold exposure showed that $\left[{ }^{18} \mathrm{~F}\right]$ FDG uptake in BAT $(P=0.028)$, liver $(P=0.028)$, and brain $(P=0.043)$ were significantly lower during the meal experiment than during the cold exposure (Figure 3E), whereas skeletal muscle uptake was significantly higher during the meal experiment $(P=0.028)$. This reflects the well-known role of skeletal muscle in postprandial glucose homeostasis. $\left[{ }^{18} \mathrm{~F}\right] \mathrm{FDG}$ uptake in WAT was not significantly different between the cold and meal experiments, although a trend was observed for higher uptake after the meal in subcutaneous WAT $(P=0.075)$.

The high postprandial $\left[{ }^{18} \mathrm{~F}\right] \mathrm{FDG}$ uptake in skeletal muscle, combined with the fact that the total mass of skeletal muscle is much larger than that of any other organ in the human body, resulted in a marked change in $\left[{ }^{18} \mathrm{~F}\right] \mathrm{FDG}$ distribution volume and a large fraction of the $\left[{ }^{18} \mathrm{~F}\right] \mathrm{FDG}$ tracer being directed to muscle. This high $\left[{ }^{18} \mathrm{~F}\right] \mathrm{FDG}$ uptake in skeletal muscle might have reduced the availability of $\left[{ }^{18} \mathrm{~F}\right] \mathrm{FDG}$ for other tissues, which is clearly visible in the cerebellum (Figure 3A). Normally, glucose uptake/ metabolism is held fairly constant in the brain, because glucose is the brain's major fuel. We therefore hypothesized that this tracer competition might have underestimated true glucose uptake in BAT. To correct for this, we also expressed the $\mathrm{SUV}_{\text {mean }}$ in the tissues as a percentage of total $\left[{ }^{18} \mathrm{~F}\right] \mathrm{FDG}$ uptake in the cerebellum (Figure 3F) (25). We chose the cerebellum as a representative brain region because it was shown previously that cold exposure does not affect metabolism in the cerebellum (26), and the cerebellum is the most reliable reference area in the brain during mild hyperglycemic conditions (25). As shown in

TABLE 1

Effect of the meal and cold exposure on metabolic, cardiovascular, and thermoregulatory variables ${ }^{1}$

\begin{tabular}{|c|c|c|c|c|}
\hline \multirow[b]{2}{*}{ Variable } & \multicolumn{2}{|c|}{ Meal $(n=11)$} & \multicolumn{2}{|c|}{ Cold $(n=6)$} \\
\hline & Baseline & Meal & Baseline & Cold \\
\hline Heart rate (beats/min) & $61 \pm 7.9$ & $74 \pm 10.2^{* *}$ & $55 \pm 3.5$ & $52 \pm 3.2 *$ \\
\hline Systolic blood pressure $(\mathrm{mm} \mathrm{Hg})$ & $119 \pm 6$ & $126 \pm 6.8^{* *}$ & $120 \pm 9.2$ & $133 \pm 8.9^{*}$ \\
\hline Diastolic blood pressure $(\mathrm{mm} \mathrm{Hg})$ & $70 \pm 6.1$ & $71 \pm 6.8$ & $73 \pm 3.2$ & $82 \pm 6.2^{*}$ \\
\hline Mean skin temperature $\left({ }^{\circ} \mathrm{C}\right)$ & $33.2 \pm 0.4$ & $33.5 \pm 0.4^{* *}$ & $32.7 \pm 0.3$ & $28.8 \pm 0.5^{*}$ \\
\hline Core temperature $\left({ }^{\circ} \mathrm{C}\right)$ & $36.9 \pm 0.1$ & $36.8 \pm 0.3^{*}$ & $36.9 \pm 0.2$ & $36.9 \pm 0.2$ \\
\hline Proximal temperature $\left({ }^{\circ} \mathrm{C}\right)$ & $34.2 \pm 0.3$ & $35.0 \pm 0.4^{* *}$ & $33.3 \pm 0.6$ & $30.8 \pm 1.2^{*}$ \\
\hline Distal temperature $\left({ }^{\circ} \mathrm{C}\right)$ & $31.2 \pm 1.8$ & $31.1 \pm 2.1$ & $30.8 \pm 1.2$ & $22.6 \pm 1.1^{*}$ \\
\hline Gradient proximal, distal $\left({ }^{\circ} \mathrm{C}\right)$ & $3.0 \pm 1.8$ & $3.9 \pm 2.5^{*}$ & $2.5 \pm 1.9$ & $8.2 \pm 2.0^{*}$ \\
\hline
\end{tabular}

${ }^{1}$ All values are means \pm SDs. A paired-sample $t$ test was used to analyze differences between the meal and baseline, and Wilcoxon's test was used to analyze differences between cold and baseline: ${ }^{*} P<0.05,{ }^{* *} P<0.001$. 


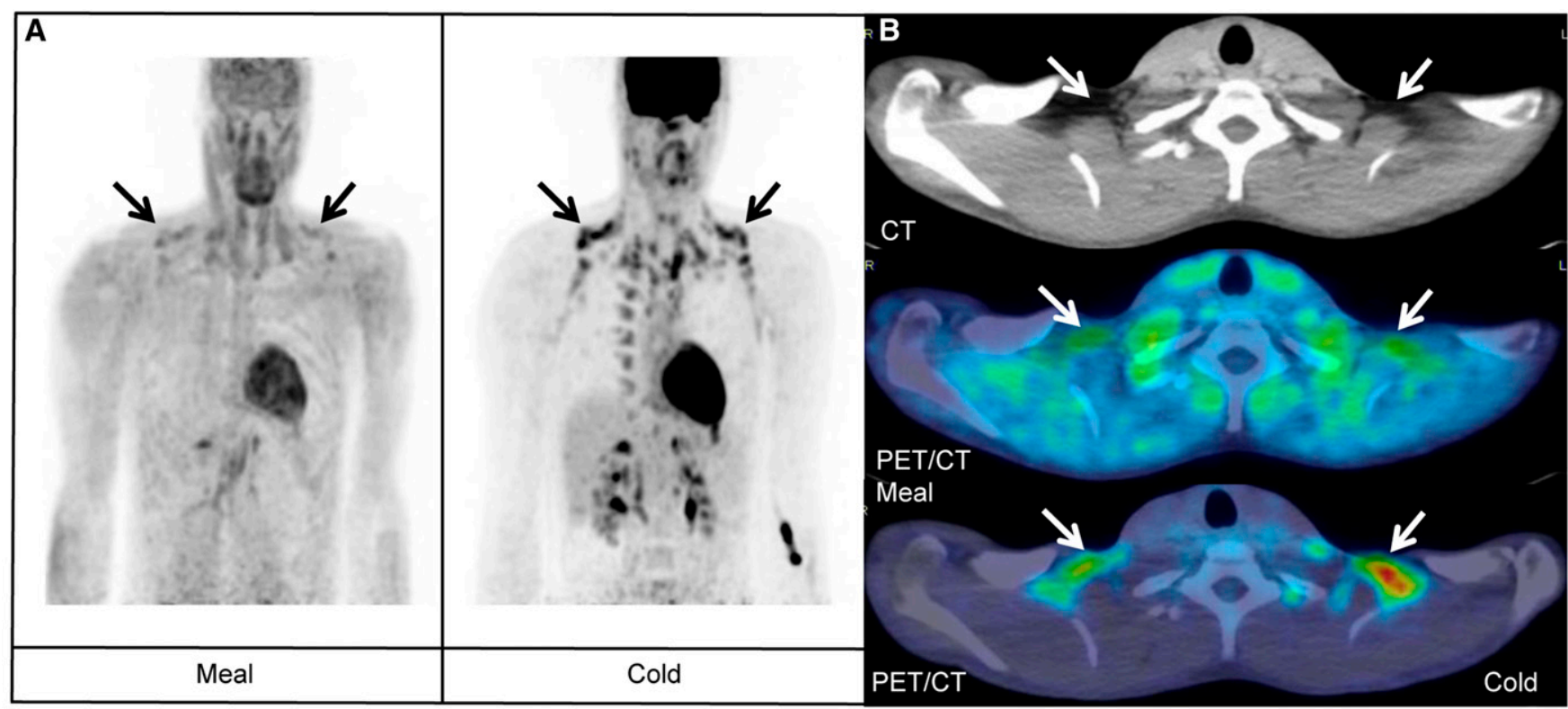

C

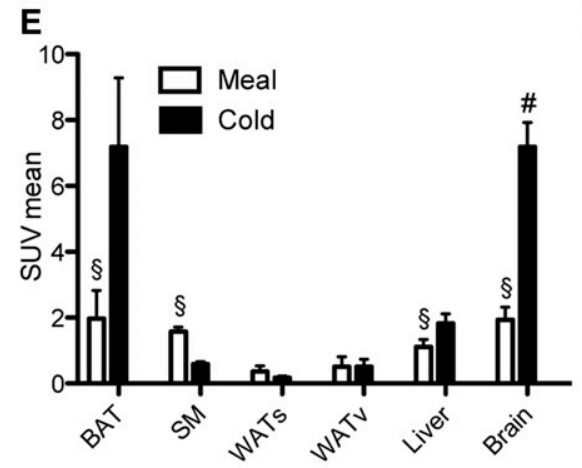

D

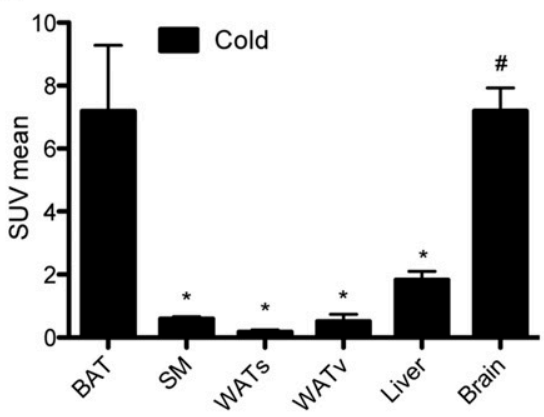

G

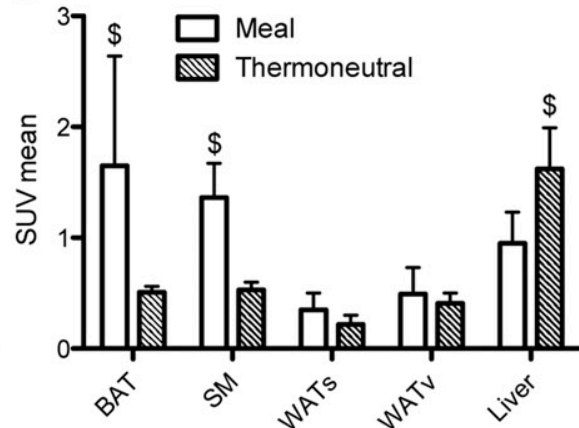

FIGURE 3. Mean $( \pm \mathrm{SD})$ uptake of $\left[{ }^{18} \mathrm{~F}\right] \mathrm{FDG}$ in BAT and other tissues during cold exposure and the postprandial state. (A) $\left[{ }^{18} \mathrm{~F}\right] \mathrm{FDG}$ PET images of one subject showing BAT activity (black arrows) after the meal (left) and during cold exposure (right). (B) Transversal CT (top) and PET/CT fusion slices of the supraclavicular region showing BAT activity (white arrows) after the meal (middle) and during cold exposure (bottom). (C) Comparison (paired-sample $t$ tests) of $\left[{ }^{18} \mathrm{~F}\right] \mathrm{FDG}$ uptake in BAT with several tissues after the meal $\left(n=11,{ }^{\#} n=8\right)$. (D) Comparison (Wilcoxon's signed-rank tests) of $\left[{ }^{18} \mathrm{~F}\right] \mathrm{FDG}$ uptake in BAT with several tissues during cold exposure $\left(n=6,{ }^{\#} n=5\right)$. (E) Comparison (Wilcoxon's signed-rank tests) of the $\left[{ }^{18}\right.$ F]FDG uptake after the meal with cold exposure $\left(n=6,{ }^{\#} n=5\right)$. (F) $\left[{ }^{18} \mathrm{~F}\right] \mathrm{FDG}$ uptake in all tissues relative to the brain (cerebellum) to indicate tracer competition. $\left[{ }^{18} \mathrm{~F}\right] \mathrm{FDG}$ uptake in the cerebellum was set at $100 \%$, because brain glucose uptake was expected to be constant during both interventions. Wilcoxon's signed-rank tests were used to determine the differences in $\left[{ }^{18} \mathrm{~F}\right] \mathrm{FDG}$ uptake between the cold and meal experiments $\left(n=6,{ }^{\#} n=5\right)$. (G) Comparison (Mann-Whitney $U$ test) of postprandial $\left[{ }^{18} \mathrm{~F}\right] \mathrm{FDG}$ uptake (current study) with the uptake in the fasted state during thermoneutral conditions measured in a previous study $(n=3)(1)$. ****Significantly different from BAT: $* P<0.05$, ${ }^{* *} P<0.001$. ${ }^{\S}$ Cold exposure significantly different from the postprandial state, $P<0.05$. ${ }^{\$}$ Postprandial state significantly different from fasted thermoneutral conditions, $P<0.05$. BAT, brown adipose tissue; CT, computed tomography; FDG, fluorodeoxyglucose; PET, positron emission tomography; SM, skeletal muscle; SUV, standard uptake value; WATs, subcutaneous white adipose tissue; WATv, visceral white adipose tissue.

Figure $3 \mathrm{~F},\left[{ }^{18} \mathrm{~F}\right] \mathrm{FDG}$ uptake in BAT (and the other tissues) was possibly underestimated during postprandial conditions and glucose uptake in BAT in the postprandial state may be comparable with that in the cold-stimulated condition.
In addition, we compared the postprandial $\left[{ }^{18} \mathrm{~F}\right] \mathrm{FDG}$ uptake with the uptake in the fasted state measured during thermoneutral conditions in a previous study $(n=3)(1) .\left[{ }^{18} \mathrm{~F}\right] \mathrm{FDG}$ uptake in BAT was significantly higher during the postprandial 
state than during the fasted thermoneutral (FTN) conditions (meal: $1.65 \pm 0.99$; FTN: $0.51 \pm 0.05 \mathrm{SUV}_{\text {mean }} ; P=0.024$; Figure $3 \mathrm{G}$ ), which confirmed an increase in postprandial BAT glucose uptake. Furthermore, postprandial $\left[{ }^{18} \mathrm{~F}\right]$ FDG uptake in skeletal muscle was higher (meal: $1.36 \pm 0.31 \mathrm{SUV}_{\text {mean }}$; FTN: $0.54 \pm 0.07 \mathrm{SUV}_{\text {mean }} ; P=0.01$ ), whereas uptake in the liver was lower (meal: $0.95 \pm 0.28 \mathrm{SUV}_{\text {mean }}$; FTN: $1.62 \pm 0.36 \mathrm{SUV}_{\text {mean }}$; $P=0.024)$ than in the FTN conditions. Unfortunately, we could not obtain the $\left[{ }^{18} \mathrm{~F}\right] \mathrm{FDG}$ uptake values in the brain during the FTN conditions.

We also analyzed the relations between BAT and energy expenditure in both experiments. Interestingly, a significant relation was found between CIT and cold-induced BAT activity $(r=0.83$, $P=0.042 ; n=6)$. However, no association was found between postprandial BAT activity and DIT ( $r=0.11$, NS; $n=11)$. Finally, we found no relation between cold-induced BAT activity and postprandial BAT activity $(r=-0.49$, NS; $n=6)$.

\section{Hormones, metabolites, and cold acclimatization}

As expected, the intake of the carbohydrate-rich meal significantly suppressed lipolysis already after $30 \mathrm{~min}$, as shown by the decrease in plasma free fatty acid $(P<0.001)$ and free glycerol $(P=0.031)$ concentrations, and remained significantly suppressed during the entire experiment. The meal significantly increased plasma glucose concentrations at all time points $(P<0.001)$ and plasma insulin concentrations (30 min: $P=0.004 ; 60$ and $120 \mathrm{~min}: P<0.001)$. Norepinephrine concentrations tended to increase after the meal $(P=0.10)$. In contrast, cold exposure increased lipolysis, as evidenced by an increase in free fatty acids $(P=0.028)$ and free glycerol concentrations (Table 2). Furthermore, plasma norepinephrine concentrations increased significantly during cold exposure $(P=0.028)$, which suggested increased sympathetic norepinephrine spill over. We found no correlation between postprandial norpinephrine concentrations and both BAT activity and DIT. In addition, no correlation was found between norpinephrine and cold-induced BAT activity and thermogenesis. We found a relation between plasma insulin concentrations (AUC) and BAT activity $(r=0.61, P=0.045)$, whereas no relation was found between plasma glucose concentrations (AUC) and BAT activity $(r=-0.08, P=0.812)$.

Interestingly we observed a negative relation between the average outdoor temperatures during the $2 \mathrm{wk}$ previous to the experiment (obtained from a local weather station) and postprandial $\left[{ }^{18} \mathrm{~F}\right] \mathrm{FDG}$ uptake in BAT $(r=-0.72, P=0.012$; Figure 4A), subcutaneous WAT ( $r=-0.60, P=0.046$; Figure 4B), and visceral WAT ( $r=-0.83, P=0.002$; Figure $4 \mathrm{C}$ ).

\section{DISCUSSION}

We showed postprandial glucose uptake in BAT in lean young men. We found that the average $\left[{ }^{18} \mathrm{~F}\right] \mathrm{FDG}$ uptake in BAT after a high-calorie, carbohydrate-rich meal was higher than that in WAT and the liver. In fact, $\left[{ }^{18} \mathrm{~F}\right] \mathrm{FDG}$ uptake in BAT tended to be higher than that in skeletal muscle, which is well known for its role in postprandial glucose homeostasis, but was comparable with that in the brain. Furthermore, $\left[{ }^{18} \mathrm{~F}\right] \mathrm{FDG}$ uptake in BAT during the postprandial state was significantly higher than that during the fasted state (during thermoneutral conditions) in a previous study (1). These results indicate that a single meal may be able to activate human BAT.

The absolute magnitude of postprandial BAT activity was lower than that of cold-induced BAT activity, which agrees with the findings in rodent studies (7). However, postprandial BAT activity may have been underestimated because of the high tracer uptake in skeletal muscle, thereby diminishing tracer bioavailability for other tissues. This was clearly illustrated by a decrease in $\left[{ }^{18} \mathrm{~F}\right] \mathrm{FDG}$ uptake in the cerebellum, which glucose uptake/metabolism was expected to be constant during both experimental conditions. This unexpected decrease in $\left[{ }^{18} \mathrm{~F}\right] \mathrm{FDG}$ uptake was observed previously during postprandial mild hyperglycemic conditions $(110-160 \mathrm{mg} / \mathrm{dL}, \sim 6.2-8.9 \mathrm{mmol} / \mathrm{L})$ (25). Adjustment for this "stealing effect" by expressing $\left[{ }^{18} \mathrm{~F}\right]$ FDG uptake relative to the cerebellum, suggests that postprandial glucose uptake in BAT is comparable with cold-induced BAT activation. Note that this adjustment assumes that glucose uptake in the cerebellum is unaffected by meal consumption. In addition to the stealing phenomenon, $\left[{ }^{18} \mathrm{~F}\right] \mathrm{FDG}$ uptake in the brain could also be reduced because of an increased saturation of the glucose transporters by glucose originating from the meal (27). Nevertheless, postprandial $\left[{ }^{18} \mathrm{~F}\right]$ FDG uptake was highest in the BAT of all peripheral tissues studied.

Thus far, an effect of meal consumption on BAT activity in humans has not been studied directly. A recent study in humans examined the effects of a high-fat meal on BAT activity; however, these measurements were combined with cold exposure (28). $\left[{ }^{18} \mathrm{~F}\right] \mathrm{FDG}$ uptake in BAT on cold exposure was

TABLE 2

Hormone and metabolite concentrations in the postprandial state and during cold exposure ${ }^{l}$

\begin{tabular}{|c|c|c|c|c|c|c|}
\hline \multirow[b]{2}{*}{ Variable } & \multicolumn{4}{|c|}{ Meal $(n=11)$} & \multicolumn{2}{|c|}{ Cold $(n=6)$} \\
\hline & Baseline & Diet, $30 \mathrm{~min}$ & Diet, $60 \mathrm{~min}$ & Diet, $120 \mathrm{~min}$ & Baseline & Cold, $60 \mathrm{~min}$ \\
\hline Glycerol free $(\mu \mathrm{mol} / \mathrm{L})$ & $51.8 \pm 12.5$ & $39.8 \pm 9.8^{*}$ & $32.7 \pm 15.4^{*}$ & $28.6 \pm 15.3^{* *}$ & $55.9 \pm 10.8$ & $123 \pm 36^{*}$ \\
\hline Triglycerides $(\mu \mathrm{mol} / \mathrm{L})$ & $750 \pm 253$ & $926 \pm 417$ & $934 \pm 422$ & $815 \pm 307$ & $776 \pm 234$ & $811 \pm 273$ \\
\hline Glucose $(\mathrm{mmol} / \mathrm{L})$ & $5.1 \pm 0.2$ & $7.9 \pm 1.3^{* *}$ & $7.2 \pm 1.3^{* *}$ & $6.6 \pm 0.8^{* *}$ & $5.1 \pm 0.2$ & $5.0 \pm 0.2$ \\
\hline Insulin (mU/L) & $12.5 \pm 3.3$ & $155 \pm 99 *$ & $120 \pm 33^{* *}$ & $124 \pm 59^{* *}$ & $12.3 \pm 2.1$ & $12.7 \pm 1.7$ \\
\hline Adrenaline $(\mathrm{ng} / \mathrm{L})$ & $32.0 \pm 10.6$ & $26.3 \pm 9.3$ & $28.6 \pm 12.6$ & $32.0 \pm 12.6$ & $29.6 \pm 9.1$ & $26.2 \pm 11.8$ \\
\hline
\end{tabular}

${ }^{1}$ All values are means \pm SDs. ANOVA with Bonferroni correction was used to analyze differences between the meal and baseline, and Wilcoxon's test was used to analyze differences between cold and baseline: $* P<0.05$, $* * P<0.001$. 

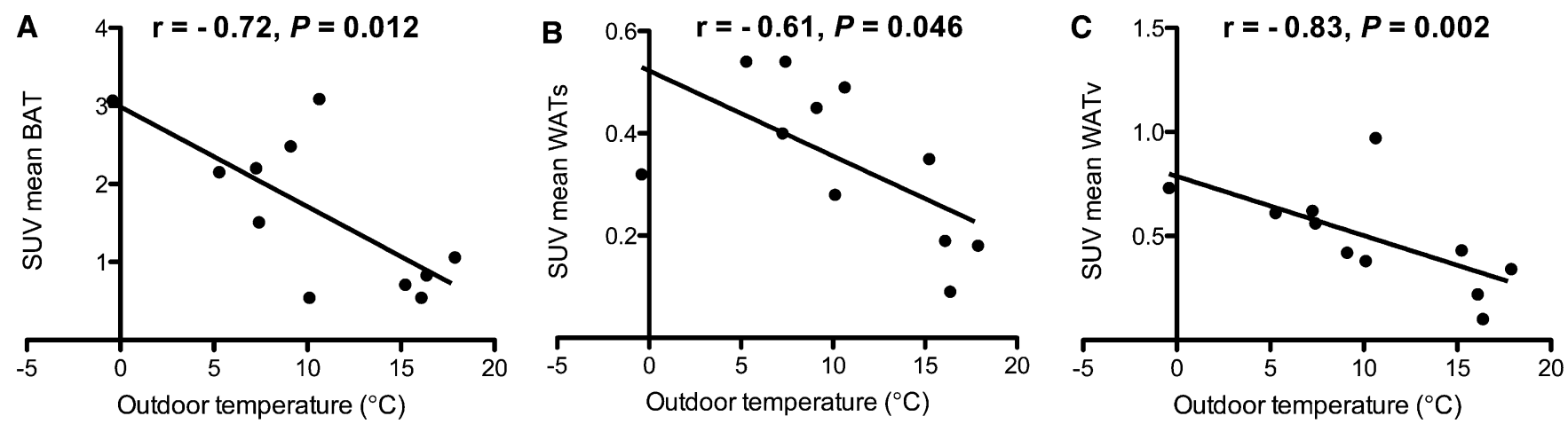

FIGURE 4. Relation between postprandial $\left[{ }^{18} \mathrm{~F}\right] \mathrm{FDG}$ uptake in BAT (A), WATs (B), and WATv (C), with the mean outdoor temperature over 2 wk previous to the meal experiment. BAT, brown adipose tissue; FDG, fluorodeoxyglucose; r, Pearson correlation coefficient; WATs, subcutaneous white adipose tissue; WATv, visceral white adipose tissue.

higher when subjects were in the fasted state than in the fed (high-fat) state. Although these results seem contrary to our findings, they were confounded by high glucose uptake in skeletal muscle after the high-fat meal, which precludes separation of the effects of cold from the effect of meal on BAT activity. In fact, the authors also concluded that the lower uptake in BAT was likely a result of tracer dilution by skeletal muscle. They did not measure uptake in the brain, although the PET image depicted in their study indicates reduced postprandial brain $\left[{ }^{18} \mathrm{~F}\right] \mathrm{FDG}$ uptake compared with cold exposure. The advantage of our study was that we did not combine the postprandial study with cold exposure in one single experimental test, which allows us to directly test the effect of a single meal on BAT activity.

Another human study investigated the effects of insulin infusion (hyperinsulinemic euglycemic clamp) on glucose uptake in BAT (in a warm environment) and found that the uptake rate was higher than that in WAT and comparable with that in skeletal muscle, which indicated that BAT is an insulin-sensitive tissue (5). In contrast with cold exposure, they did not find increased BAT perfusion, which shows that insulin by itself does not induce BAT thermogenesis, for which BAT perfusion is an indirect measure. Furthermore, they did not find increased plasma norepinephrine concentrations, which suggests no sympathetic stimulation by insulin. Whether, in the current study, glucose uptake in BAT reflected BAT thermogenesis or solely insulinmediated glucose uptake without concomitant heat production could not be determined. Interestingly, we found a relation between plasma insulin concentrations and BAT activity, which indicated a likely role for insulin in mediating BAT glucose uptake and possibly thermogenesis.

In rodents, experiments have repeatedly shown BAT activation after single meals. It has been shown that a single meal increases mitochondrial uncoupling (15) and blood flow (18) in BAT and oxygen consumption in vitro $(19,20)$. This is likely regulated via the SNS, because norpinephrine concentrations and turnover also increased after a single meal (17). In the current study, norpinephrine concentrations tended to increase after the meal, which suggests postprandial sympathetic stimulation. We, however, did not find a relation between postprandial $\left[{ }^{18} \mathrm{~F}\right] \mathrm{FDG}$ uptake in BAT and plasma norpinephrine. The increased sympathetic drive after a single meal found in rodents was possibly regulated via elevated concentrations of glucose and insulin activity sensed by the hypothalamus (7). This might also be true for insulin in humans, as demonstrated by its relation with $\left[{ }^{18} \mathrm{~F}\right] \mathrm{FDG}$ uptake in BAT in the current study.

Although $\left[{ }^{18} \mathrm{~F}\right]$ FDG PET/CT scanning merely measures glucose uptake, it would be tempting to suggest that the meal induced BAT thermogenesis. However, we found a relation between BAT activity and DIT. Note that the potential contribution of BAT to the facultative part of DIT is difficult to detect via whole-body energy expenditure (29). Unfortunately, we were not able to distinguish between the facultative and obligatory part of DIT in the current experiment. With respect to cold exposure, we did find a correlation between BAT activity and CIT, which has been shown previously $(3,5,6)$, although not consistently $(1,24)$.

Interestingly, we found a relation between postprandial BAT activity and the outdoor temperature averaged over 2 wk previous to the experiment. This was likely a result of adaptation of BAT to long-term cold exposure (ie, cold acclimatization). This could suggest that the contribution of BAT to postprandial thermogenesis may be enhanced by cold acclimatization, which has been shown in rats (21). It could thus be speculated that BAT most likely contributes to postprandial glucose uptake and possibly to thermogenesis during cold seasons.

In conclusion, glucose uptake in BAT increases after a single meal in humans, which indicates a role for BAT in reducing metabolic efficiency. However, we found no direct relation between BAT activity and DIT. The quantitative contribution of BAT to DIT, as well as its role in energy balance regulation, remains to be investigated in future research. It would also be important to determine whether postprandial BAT activity is lower in overweight and obese subjects.

We thank Ivo Pooters (Maastricht University Medical Centre+) for his assistance during the experiments and Jos Stegen (Maastricht University Medical Centre+), Paul Menheere, and Nancy Hendrix (Maastricht University Medical Centre+) for their assistance with the biochemical analysis. The technical support of Mariëlle Visser, Christian Urbach, Emiel Beijer, Loek Wouters, Paul Schoffelen, and Paul Bergs (Maastricht University Medical Centre+) was highly appreciated. Finally, we thank our Literature Club for all the fruitful discussions.

The authors' responsibilities were as follows-MJV, PS, WDvML, MAvB, and BB: contributed to the study design; MJV and AAJJvdL: conducted the experiments; MJV: performed the statistical analysis; $\mathrm{BB}$ and RW: contributed to the PET-CT analysis; and MJV, PS, and WDvML: wrote the manuscript. All authors critically read the manuscript, provided suggestions for improvement, and approved the final version. None of the authors had a personal or financial conflict of interest. 


\section{REFERENCES}

1. van Marken Lichtenbelt WD, Vanhommerig JW, Smulders NM, Drossaerts JM, Kemerink GJ, Bouvy ND, Schrauwen P, Teule GJ. Cold-activated brown adipose tissue in healthy men. N Engl J Med 2009;360:1500-8.

2. Virtanen KA, Lidell ME, Orava J, Heglind M, Westergren R, Niemi T, Taittonen M, Laine J, Savisto NJ, Enerback S, et al. Functional brown adipose tissue in healthy adults. N Engl J Med 2009;360: 1518-25.

3. Yoneshiro T, Aita S, Matsushita M, Kameya T, Nakada K, Kawai Y, Saito M. Brown adipose tissue, whole-body energy expenditure, and thermogenesis in healthy adult men. Obesity (Silver Spring) 2011;19: 13-6.

4. Ouellet V, Labbé S, Blondin D, Phoenix S, Guérin B, Haman F, Turcotte E, Richard D, Carpentier A. Brown adipose tissue oxidative metabolism contributes to energy expenditure during acute cold exposure in humans. J Clin Invest 2012;122:545-52.

5. Orava J, Nuutila P, Lidell M, Oikonen V, Noponen T, Viljanen T, Scheinin M, Taittonen M, Niemi T, Enerbäck S, et al. Different metabolic responses of human brown adipose tissue to activation by cold and insulin. Cell Metab 2011;14:272-9.

6. Vijgen GH, Bouvy ND, Teule GJ, Brans B, Schrauwen P, van Marken Lichtenbelt WD. Brown adipose tissue in morbidly obese subjects. PLoS ONE 2011;6:e17247.

7. Cannon B, Nedergaard J. Brown adipose tissue: function and physiological significance. Physiol Rev 2004;84:277-359.

8. Saito M, Okamatsu-Ogura Y, Matsushita M, Watanabe K, Yoneshiro T, Nio-Kobayashi J, Iwanaga T, Miyagawa M, Kameya T, Nakada K, et al. High incidence of metabolically active brown adipose tissue in healthy adult humans: effects of cold exposure and adiposity. Diabetes 2009;58:1526-31.

9. Feldmann HM, Golozoubova V, Cannon B, Nedergaard J. UCP1 ablation induces obesity and abolishes diet-induced thermogenesis in mice exempt from thermal stress by living at thermoneutrality. Cell Metab 2009;9:203-9.

10. Rothwell NJ, Stock M. A role for brown adipose tissue in diet-induced thermogenesis. Nature 1979;281:31-5.

11. Stock MJ. Gluttony and thermogenesis revisited. Int $\mathbf{J}$ Obes Relat Metab Disord 1999;23:1105-17.

12. Kozak LP. Brown fat and the myth of diet-induced thermogenesis. Cell Metab 2010;11:263-7.

13. van Marken Lichtenbelt WD, Schrauwen P. Implications of nonshivering thermogenesis for energy balance regulation in humans. Am J Physiol Regul Integr Comp Physiol 2011;301:R285.
14. van Baak MA. Meal-induced activation of the sympathetic nervous system and its cardiovascular and thermogenic effects in man. Physiol Behav 2008;94:178-86.

15. Lupien JR, Glick Z, Saito M, Bray GA. Guanosine diphosphate binding to brown adipose tissue mitochondria is increased after single meal. Am J Physiol 1985;249:R694-8.

16. Glick Z, Wu SY, Lupien J, Reggio R, Bray GA, Fisher DA. Mealinduced brown fat thermogenesis and thyroid hormone metabolism in rats. Am J Physiol 1985;249:E519-24.

17. Glick Z, Raum WJ. Norepinephrine turnover in brown adipose tissue is stimulated by a single meal. Am J Physiol 1986;251:R13-7.

18. Glick Z, Wickler SJ, Stern JS, Horwitz BA. Regional blood flow in rats after a single low-protein, high-carbohydrate test meal. Am J Physiol 1984;247:R160-6.

19. Glick Z, Teague RJ, Bray GA, Lee M. Compositional and metabolic changes in brown adipose tissue following a single test meal. Metabolism 1983;32:1146-50.

20. Glick Z, Teague RJ, Bray GA. Brown adipose tissue: thermic response increased by a single low protein, high carbohydrate meal. Science 1981;213:1125-7.

21. Allard M, Leblanc J. Effects of cold acclimation, cold exposure, and palatability on postprandial thermogenesis in rats. Int J Obes 1988;12: $169-78$.

22. Harris JA, Benedict FG. A biometric study of human basal metabolism Proc Natl Acad Sci USA 1918;4:370-3.

23. Baecke JA, Burema J, Frijters JE. A short questionnaire for the measurement of habitual physical activity in epidemiological studies. Am J Clin Nutr 1982;36:936-42.

24. Vosselman MJ, van der Lans AA, Brans B, Wierts R, van Baak MA, Schrauwen P, Lichtenbelt WD. Systemic beta-adrenergic stimulation of thermogenesis is not accompanied by brown adipose tissue activity in humans. Diabetes 2012;6:3106-13.

25. Kawasaki K, Ishii K, Saito Y, Oda K, Kimura Y, Ishiwata K. Influence of mild hyperglycemia on cerebral FDG distribution patterns calculated by statistical parametric mapping. Ann Nucl Med 2008;22:191-200.

26. Craig AD, Chen K, Bandy D, Reiman E. Thermosensory activation of insular cortex. Nat Neurosci 2000;3:184-90.

27. Wong K-P, Sha W, Zhang X, Huang S-C. Effects of administration route, dietary condition, and blood glucose level on kinetics and uptake of 18F-FDG in mice. J Nucl Med 2011;52:800-7.

28. Vrieze A, Schopman J, Admiraal W, Soeters M, Nieuwdorp M, Verberne H, Holleman F. Fasting and postprandial activity of brown adipose tissue in healthy men. J Nucl Med 2012;53:1407-10.

29. Weststrate JA. Resting metabolic rate and diet-induced thermogenesis: a methodological reappraisal. Am J Clin Nutr 1993;58:592-601. 